\title{
Infection Prevention and Control Education in Egypt: Professional Diploma in Infection Control (PDIC)
}

\author{
Ossama Rasslan \\ President, Egyptian Society for Infection Control \\ Director, Eastern Mediterranean Regional Network for Infection Control
}

doi: 10.3396/ijic.V7i2.015.11

\section{Preamble:}

Before 2003, there was no structured infection control program in Egypt, neither at the national level nor at the peripheral facility level. There were only some individual efforts and isolated trials in some healthcare facilities. Early in 2003, an infection control program was established by collaboration between the Ministry of Health, World Health Organisation (WHO) Easter Mediterranean Regional Office (EMRO) and other relevant governmental and non-governmental healthcare authorities and organizations. Education in infection prevention and control was targeted as one of the main objectives of the infection control program. Short term infection control training courses were developed by the ministry of health in conjunction with the Egyptian Society for Infection control (ESIC) as Training of Trainers (TOT) courses. These courses were conducted in one of two forms:

- A one week per month course, over a six months period, with the three weeks gap in each month used for practical on the job training in the field.

- A one day per week course for a six months period, with field assignments and projects throughout the course, followed by the awarding of a training certificate after sitting for written, oral and practical exams.
After four years of such certified training, ESIC and the Arab Institute for Continuing Professional Development (AICPD), decided that in order to have qualified professionals to take over infection prevention and control activities in Egypt, as well as the EMRO region, it would be important to have a more comprehensive training programme, allowing candidates to get a Professional Diploma in Infection Control (PDIC).

\section{PDIC Curriculum:}

The PDIC aims at providing candidates with sufficient knowledge, skills and attitudes, essential for leading and managing Infection Prevention and Control programs in different healthcare organizations and services. The program is organized as two main courses. The first course is the basic principles and general measures for prevention and control of healthcare associated infections (HAls). The second course is the applied practices and advanced issues for prevention and control of HAls. The two courses are conducted as nine learning modules as follows:

- Basic Principles and Practices for Prevention and Control of HAls

- Support Services and Environmental Infection Prevention and Control Measures

- Infection Prevention and Control Aspects of Occupational Health Program

- Basics of Healthcare Associated Infection Epidemiology and Surveillance 
- Basics of Infection Prevention and Control Program Management

- Infection Prevention and Control Strategies in Core Healthcare Units

- Infectious Disease Process and Antimicrobial Stewardship

- Specific Infection Prevention and Control Measures

- Patient Safety Issues and Quality Improvement

The program is delivered over 14 months as part time training. The workload equals 22 credit hours, fulfilling the following activities: face to face instructions and interactive discussions, field visits and handson training and independent self-study comprising assignments and project work.

Candidates are graduates of medical schools (and very soon Nursing schools), who have successfully completed the pre-registration house officer year. Enrolment in the program is allowed three times per year at January, May and September.

Different methods of learning are delivered by expert instructors, in the form of formal didactic lectures, practical sessions, interactive workshops and structured, supervised field training.

Participants are evaluated by different methods including final summative written exams, objective structured practical exams (OSPE), periodical written assignments and final project presentation. All program participants must keep and update a logbook where they document their participation in formal teaching sessions and field work activities.

Different approaches are used to evaluate the program including participants and instructor feedback, peerreview, annual reporting and external evaluation.

\section{Participants}

Numbers: To date 360 physicians have joined 8 courses (45 participants each); comprising 2 courses in 2007/2008, 3 in 2008/2009 and 3 in 2009/2010. Participants in five courses have completed their courses, and achieved graduation. The other three are still in progress.
Nationalities: The Course participants were from 9 different Arab countries. About $90 \%$ of them were Egyptians. Other participants were from Sudan, Yemen, Iraq, Syria, Libya, Palestine, Saudi Arabia and Kuwait. Some candidates (mainly from Iraq) were funded by EMRO/WHO, and Palestinians were sponsored by the Arab Medical Union (AMU)

Affiliations: Participants were affiliated with a variety of healthcare organizations and authorities in different Arab countries including Ministry of Health $(\mathrm{MOH})$, Teaching Hospitals, Health Insurance Hospitals, Charity Hospitals, Private Hospitals, Academic Institutions \& University Hospitals, in addition to some independent physicians.

\section{Field Work}

\section{Practical Field Training}

\section{What? (Topics):}

Practical field training included a wide variety of essential topics; e.g: Hand Hygiene, Personal Protective Equipments, Disinfection \& Sterilization, Support Services (Laundry, Kitchen, Air Conditioning, Ventilation System, Water Services and Maintenance), Unit specific measures (e.g. Dialysis Unit, ICU, NICU, Burns Unit, Endoscopy Unit, CSSD, etc).

\section{Where? (Training Centres):}

Many General or Specialized tertiary hospitals, belonging to the ministry of health, university or teaching hospitals, have been included in the practical training sessions, depending on: the relevance of their specialty to the training topic, how well they are equipped and the presence of expert trainers within the facilities

\section{How many? (Training sessions):}

Each of the two PDIC courses (Basic and Advanced) involved 7-8 full day time, supervised, practical training sessions. Participants were divided into groups of ten to twelve people, each under supervision of an experienced trainer. 


\section{Who? (Supervisors and Trainer):}

Each training session was conducted by a specialty expert with relevant experience in the specialty, under the supervision of a Faculty staff member (a professor; or senior IPC consultant).

\section{Field Projects}

Participants of each PDIC class were divided (at the beginning of the course) into groups of five. Each group was under the supervision of a staff member. Every participant agreed to conduct a field project throughout the course, and to present their findings, conclusion and recommendations at the end of the project.

A variety of topics were targeted for conducting field projects; e.g.:

- Situation analysis and benchmarking among different facilities

- Surveillance studies in different settings

- Intervention studies in some critical care units.

- Outbreak investigation (MRSA, VRSA, Food poisoning, etc)

- Developing and implementing an IPC program, and measuring the impact.

- Developing an education program

\section{Output and Influence - how the graduates'}

experience is being applied today:

\section{Practice:}

- ICDs

More than $70 \%$ of the graduates are now working as Infection control doctors (ICDs: Infection control team leaders) in different healthcare facilities in Egypt and in some Arab countries. In other words about $15 \%$ of the secondary and tertiary care hospitals in different healthcare authorities in Egypt are currently covered by PDIC Graduates, and the number is increasing

- Advisory Work

A number of graduates are working now as consultants and Advisory Board Members in large governmental and non governmental hospitals.

- Strategic Work

A group of graduates are working as strategic planners and as Infection Prevention and Control Directors at the central level of $\mathrm{MOH}$, (the organization of Specialized Medical Centres and Teaching Hospitals \& Institutes Authority in Egypt).

Table I. Graduation Exams Results

\begin{tabular}{rrrrr} 
Class & Total number & Pass & Fail & Success Rate \\
\hline 1 & 45 & 37 & 8 & $79 \%$ \\
\hline 2 & 45 & 36 & 9 & $76 \%$ \\
\hline 3 & 45 & 39 & 6 & $85 \%$ \\
\hline 4 & 45 & 38 & 7 & $82 \%$ \\
\hline 5 & 45 & 39 & 6 & \\
\hline 6 & 45 & & & \\
\hline 7 & 45 & & Course in progress \\
\hline 8 & 45 & & &
\end{tabular}

Failed Candidates retook their exams 6 months later, and all of them passed. 
- Academic Institutions

Some of the graduates are University Staff members in the schools of Medicine, and they are currently responsible for running Infection Prevention and Control Courses and Master Degrees in their institutions in Cairo, Ain Shams, Alexandria and Misr International Universities.

\section{Research}

Many graduates have published original research articles, in different infection prevention and control aspects and surveillance issues, in local, regional and international peer-reviewed journals.

\section{Recognition}

- Locally

PDIC is recognized by the Egyptian Medical Syndicate (EMS). Graduates are registered in the EMS Registry as Infection Control Specialists.

PDIC is recognized by the Egyptian Board for Medical Specialties PDIC holders, joining the Board course have a one year period deducted from the 3 years' mandatory Board course of the Egyptian Board of Infection Control Regionally:

PDIC is recognized by EMRO/WHO and The Arab Medical Union (AMU). Both Organizations have specific scholarships and grants to cover the PDIC course fees for candidates from some Arab countries for example, Palestine and Iraq.

- Internationally

PDIC is endorsed by The International Federation for Infection Control (IFIC).

\section{Progress}

- Recent

The Basic course of PDIC has been conducted in Syria (one course) and Libya (two) in cooperation with EMRO.

PDIC is currently undergoing an accreditation process by the International Board for Certified Trainers through the Egyptian Supreme Council for Universities in Egypt and is expecting recognition for accreditation within the next few months.

In cooperation with Webber training, an Arabic version for the PDIC course will be posted on the Webber training web site.

- Future Plans

To extend the PDIC Course to other medical and paramedical specialties, namely Dentists, Nursing Staff and Pharmacists.

To develop specialized courses for Laboratory Technicians and Veterinarians.

To establish a consultation centre (from PDIC staff and graduates) to prepare healthcare facilities for accreditation in infection control areas.

To conduct the PDIC course in other countries in the region and to develop an e-learning module of PDIC, for distant learning in remote countries in the region. 